\title{
Parametric Analysis CFD of the Hydraulic Performance of a Centrifugal Pump with Applications to the Dredging Industry
}

\author{
Javier Cardenas Gutierrez ${ }^{1}$, Guillermo Valencia Ochoa ${ }^{2}$ and Jorge Duarte Forero ${ }^{2, *}$ \\ ${ }^{1}$ Department of Civil Engineering, Universidad Francisco de Paula Santander, Cúcuta- Norte de Santander, Colombia \\ ${ }^{2}$ Department of Mechanical Engineering, Universidad del Atlántico, Puerto Colombia Área Metropolitana de Barranquilla - Atlántico, \\ Colombia
}

Received 22 April 2019; Accepted 20 January 2020

\begin{abstract}
The present study aims to use the analysis of CFD in a centrifugal dredge pump, to predict by mathematical correlations the effect that changes in the main variables of the dredging process would have on the behavior and efficiency of the pump. The OpenFOAM ${ }^{\circledR}$ open source software is used for the development of the study, through which a series of operating conditions that the dredging pump experiences in its operation were reproduced. The information collected from the output variables in the pump allowed us through statistical analysis, the development of mathematical correlations that allow us to directly identify the relationships between the process variables and their influence on the pump behavior (suction pressure, discharge pressure, total dynamic head, NPSHr and efficiency). The results obtained indicate that the simulation process allows a high prediction to be obtained with respect to the actual pump conditions (error below 4\%). Mathematical correlations demonstrated efficiency for the operating range of work from $83 \%$ to $64 \%$. Additionally, the NPSHr analysis allows defining operating limits that avoid adverse effects such as cavitation.
\end{abstract}

Keywords: Centrifugal pumps; CFD; Correlation; Dredging; Parametric.

\section{Introduction}

In industrial processes that involve fluid movement, centrifugal pumps represent an important part of the energy expenditure of the process [1]. Additionally, the fluid displacement process is subject to different conditions that reduce efficiency, such as friction losses, leaks, cavitation phenomena, among others. Given the importance of energy savings today, industries are in need of looking for ways to improve the productivity and performance of operating equipment, especially centrifugal pumps [2].

To improve the productivity and performance of equipment such as centrifugal pumps requires a complex analysis of the phenomena that occur inside. In search of these improvements, different types of methodologies have been carried out that have allowed improvements in its design and operation process [3-12].

Mathematical models have been one of the methods used in the development of centrifugal pumps. In this way, it is possible to perform a simple analysis of the performance parameters [13-16]. However, for complex industrial processes, the analysis becomes tedious and impractical. The experimental methodology is another means of analysis for the search of empirical correlations that allow the estimation of the behavior of the pump. However, the number of variables normally found in industrial processes makes the development of experiments too expensive in the vast majority of cases.

Due to the limitations of the two methods described above, analysis using computational fluid dynamics is most frequently used for the study of centrifugal pumps [17-19]. The main advantage of the analysis in CFD is its ability to study different operating conditions, considerably reducing the time and cost of the studies. Maluta et al. [20] conducted a study of a solid-liquid mixture pump, using the EulerianEulerian model. Heng et al. [21] studied the effect of solid particles of the fluid during its transport through pipes. Tarodiya et al. [22] investigated the efficiency of a centrifugal pump that carries wastewater. Currently, the capacity of computers has allowed CFD analyzes to become increasingly accurate and require less processing resources. Research shows that the prediction of analyzes in CFDs show errors of less than $8 \%$.

Due to these characteristics, CFD analysis has become a powerful tool for the study of various industrial processes, including the study of centrifugal pumps [23][24]. In the present study, a methodology is developed for the analysis of the behavior and performance of a centrifugal pump used in the dredging process, through the analysis in CFD. Therefore, the OpenFOAM ${ }^{\circledR}$ and SALOME ${ }^{\circledR}$ open source software was used to evaluate the influence of the operating parameters such as flow rate, suction angle inclination, suction depth and density, in the behavior and performance of the pump. In this way, the creation of mathematical correlations is sought that allow to precisely define the best-operating conditions and reduce the effects that produce decreases in the efficiency of the pump, such as turbulence and cavitation.

\section{Numerical methodology}

The free OpenFOAM ${ }^{\circledR}$ software is used for the study in CFD. This open-source software allows us to solve fluid mechanics problems [25]. In this way, it is not necessary to acquire high- 
cost licenses. Table 1 shows the geometric details of the dredge pump. Based on this information and from the manufacturer's data, the CAD model is built using the SALOME $^{\circledR}$ software. The CAD model of the pump is shown in Figure 1. Figure 2 shows the experimental assembly and instruments used in the study. The computational domain is modeled using the multiple reference frame approach, which consists of defining two zones: a fixed one consisting of the pipes (suction and discharge line) and the casing, and a rotary consisting of the impeller. The boundary conditions used in the computational domain are shown in Table 2.

Table 1. Geometric characteristics of the dredge pump.

\begin{tabular}{l|l}
\hline \multicolumn{2}{c}{ Impeller detail } \\
\hline Type & Closed \\
Material & Cast iron \\
Number blades & 3 \\
Diameter [m] & 1.8 \\
\hline
\end{tabular}

Table 2. Domain boundary conditions.

\begin{tabular}{l|l}
\hline \multicolumn{2}{c}{ Boundary conditions } \\
\hline Suction line: & Inlet pressure \\
Discharge line: & Output velocity \\
Impeller: & Rotation velocity \\
\hline \multicolumn{2}{c}{ Types of domains } \\
\hline Stationary domain: & Casing and pipelines \\
Rotating domain: & Impeller \\
\hline
\end{tabular}

The meshing process was carried out using the SALOME ${ }^{\circledR}$ tool called BlockMesh. To improve the quality of the mesh, local mesh control was implemented. Due to the different changes of geometric sections, a tetrahedral mesh was used for the entire domain. The resulting final mesh was evaluated based on the orthogonal quality, aspect ratio and element quality parameters (Fig. 3a). The results obtained from this evaluation are shown in Table 3 and Fig. $3 b$.

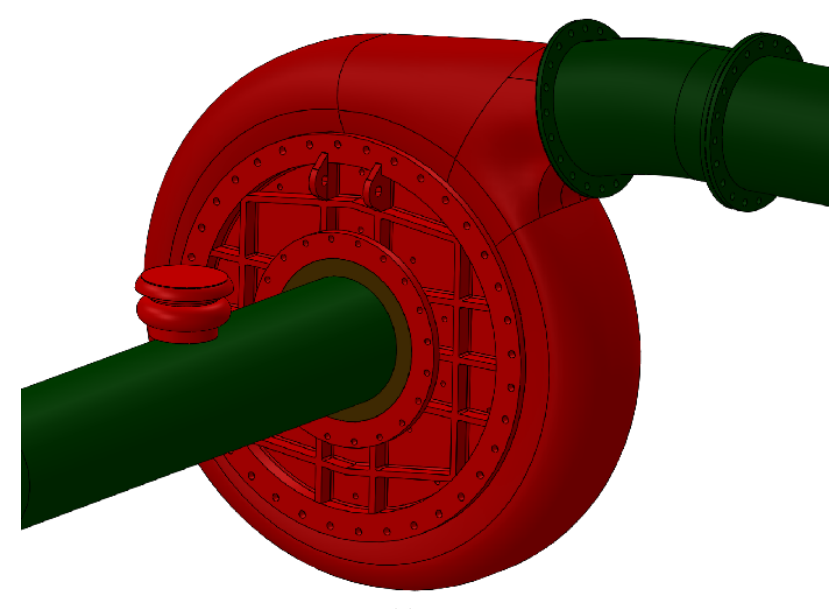

(a)

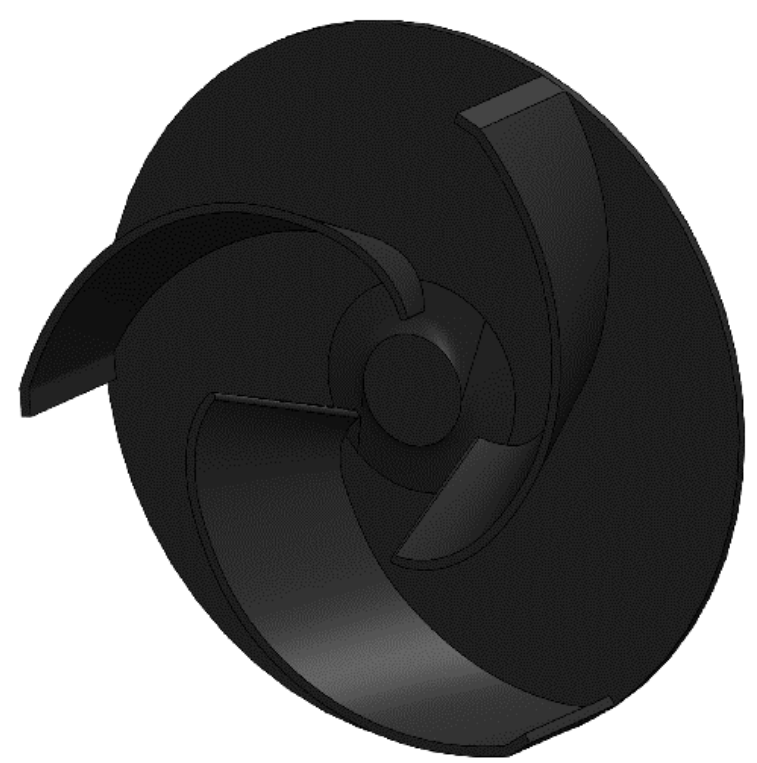

(b)

Fig.1. Dredge pump CAD model, (a) casing and (b) impeller.

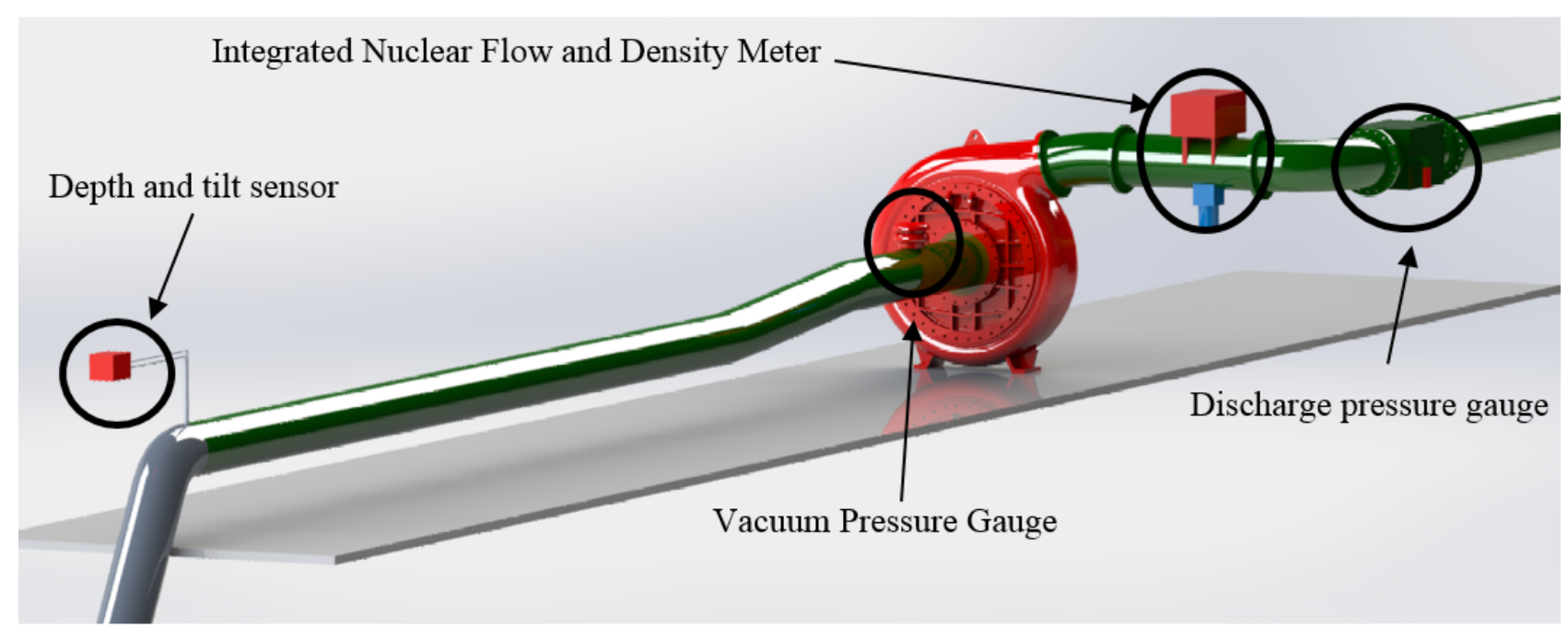

Fig. 2. Experimental assembly and instruments used 
Table 3. Mesh quality assessment.

\begin{tabular}{c|c|c|c}
\hline Parameter & Mean & $\begin{array}{c}\text { Standard } \\
\text { deviation }\end{array}$ & Quality \\
\hline $\begin{array}{c}\text { Orthogonal } \\
\text { quality }\end{array}$ & 0.95 & $5.25 \times 10^{-2}$ & Good \\
$\begin{array}{c}\text { Aspect ratio } \\
\text { Element } \\
\text { quality }\end{array}$ & 1.25 & 0.10 & Good \\
Nodes: 1253504 & $4.21 \times 10^{-2}$ & Good \\
\hline
\end{tabular}

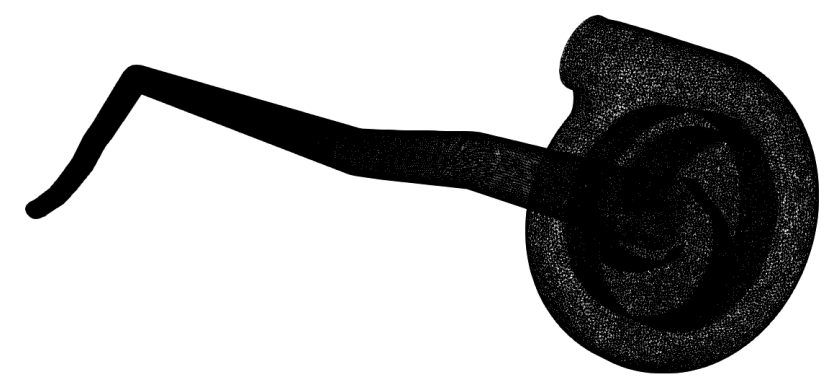

(a)

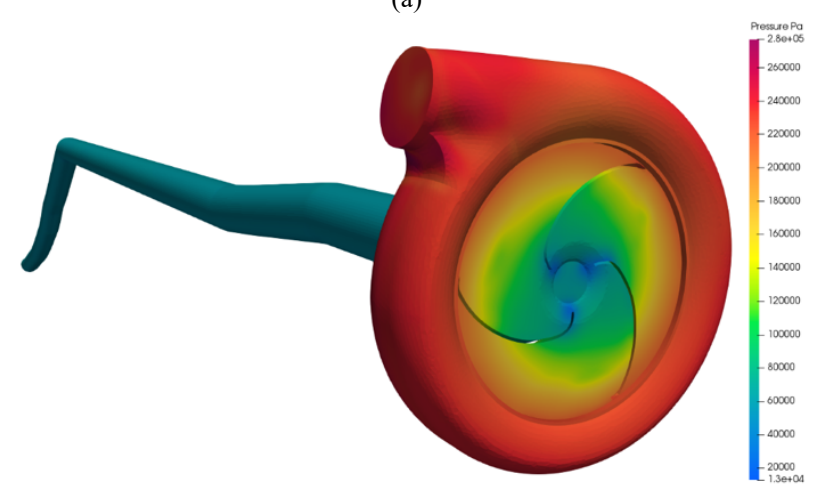

(b)

Fig. 3. CFD analysis a) Mesh used in study b) pressure profile inside the pump

To model the behavior of the pump, the $\mathrm{k}-\varepsilon$ model was used, taking into account the effect of gravity on the fluid. The effect of cavitation was modeled considering the working fluid as a homogeneous multiphase flow [26][27]. For the convergence criterion, an RMS residual with a minimum value of $1 \times 10^{-4}$ was used.

In order to verify the reliability of the results obtained in the simulation, a comparison was made between the characteristic curve of the pump obtained from the experimental data and the simulated data. The results of the comparison are shown in Figure 4. A maximum difference of $4 \%$ was observed between the experimental and simulated values, which indicates that the simulation process is close to the actual operating conditions of the pump. The magnitude of the error found is similar to other pump model investigations [22].

\section{Experimental Design}

To analyze the different operating conditions of the dredge pump, an experimental design was developed, using the CCD (Box-Wilson) algorithm to predict the spacing of the experiment matrix. Using the CCD algorithm, a design matrix of 27 elements was determined. At each of these points, the measurements of the parameters of suction pressure, discharge pressure, total dynamic head, NPSHr, and efficiency were recorded, through the development of simulations.

With the results obtained in the experimental design, we proceed to develop mathematical functions that allow us to relate the output variables with the typical input variables in the dredging process (see Table 4). This process was carried out by multiple regression using Statgraphics statistical software.

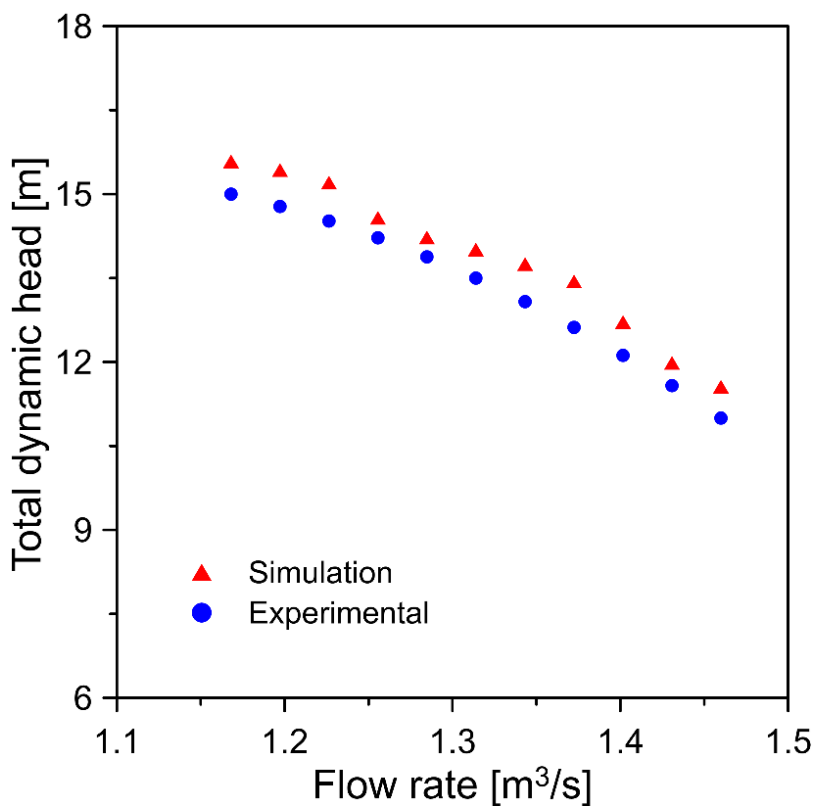

Fig. 4. Characteristic curve of the pump obtained experimentally and numerically.

Table 4. Input variables in the dredging process.

\begin{tabular}{c|c|c|c|c|c}
\hline $\begin{array}{c}\text { Symb } \\
\text { ol }\end{array}$ & Variables & $\begin{array}{c}\text { Lo } \\
\text { w }\end{array}$ & $\begin{array}{c}\text { Mediu } \\
\text { m }\end{array}$ & $\begin{array}{c}\text { Hig } \\
\text { h }\end{array}$ & Units \\
\hline $\mathrm{v}$ & Flow velocity & 2 & 5 & 8 & $\mathrm{~m} / \mathrm{s}$ \\
$\theta$ & $\begin{array}{c}\text { Suction angle } \\
\text { inclination }\end{array}$ & 35 & 65 & 95 & $\circ$ \\
$\mathrm{h}$ & $\begin{array}{c}\text { Suction depth } \\
\rho\end{array}$ & 0 & 8 & 16 & $\mathrm{~m}$ \\
\hline
\end{tabular}

\section{Results and Discussion}

Eq.1 shows the suction pressure $\left(\mathrm{P}_{\mathrm{s}}\right)$ as a function of the input variables defined in Table 4, obtained using the regression model. The adjustment coefficient reached was $\mathrm{R}^{2}=85.2 \%$, which is an acceptable value for the type of model [27].

$$
\begin{aligned}
& P_{s}=-252343+5723.2 \cdot(\theta)+258325 \cdot(\rho)+22646 \cdot \\
& (h)-47872 \cdot(v)-23.782 \cdot(\theta)^{2}+34867 \cdot(\rho)^{2}+ \\
& 512.24 \cdot(h)^{2}-3829.3 \cdot(\theta) \cdot(\rho)+29.73 \cdot(\theta) \cdot \\
& (h)+513.2 \cdot(\theta) \cdot(v)-21216 \cdot(\rho) \cdot(h)+2142.3 \cdot \\
& (h) \cdot(v) .
\end{aligned}
$$

Eq.1 analyzes the effect of the inclination of the suction angle on the suction pressure of the pump for different flow density conditions. The results obtained are shown in Figure 5.

Figure 5 shows that, in general, the increase in the angle of inclination produces a reduction in the suction pressure. The foregoing is attributed to the increase in the loss of load caused by the more abrupt change of direction exerted in the fluid while the suction line increases its inclination. Similarly, 
it is shown that the increase in density causes a reduction in suction pressure. This is attributed to the greater number of solid particles present in the fluid, so more energy is needed to pump the fluid. Similar results are reported in other investigations [28][29].

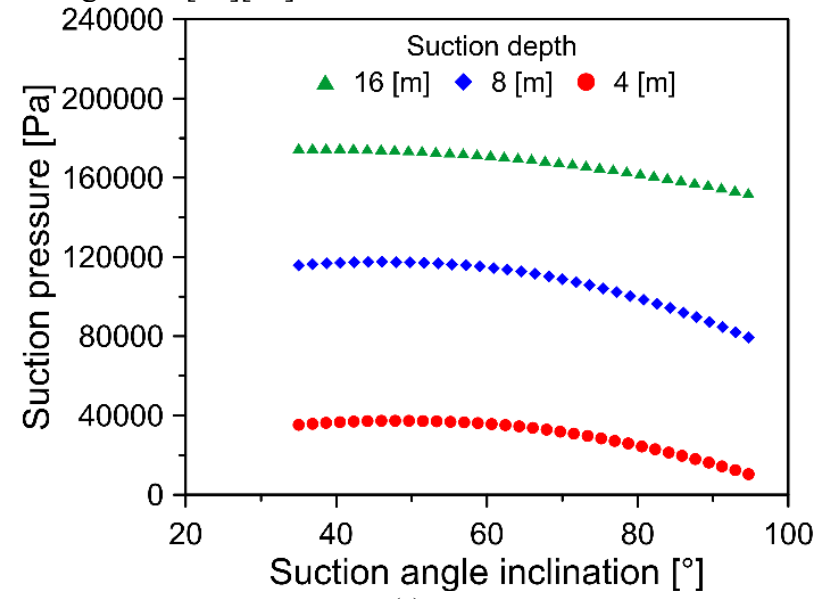

(a)

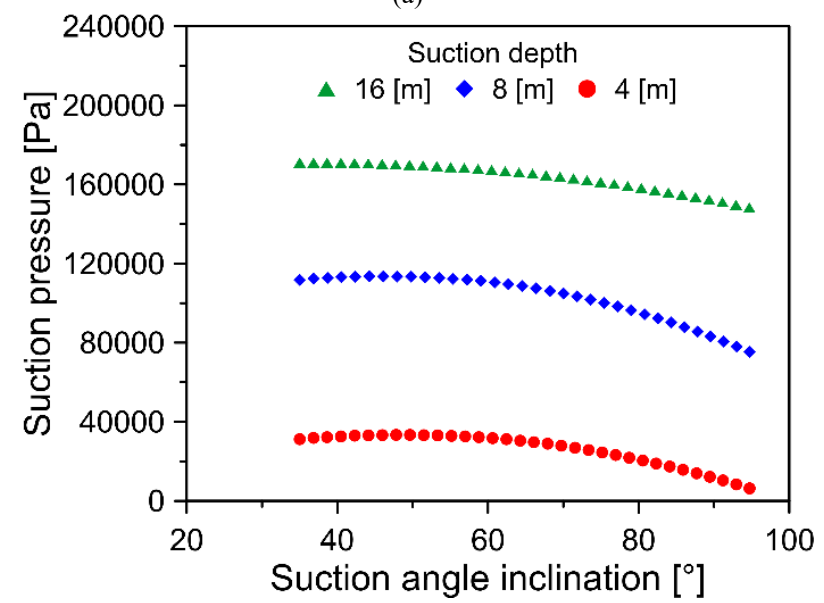

(b)

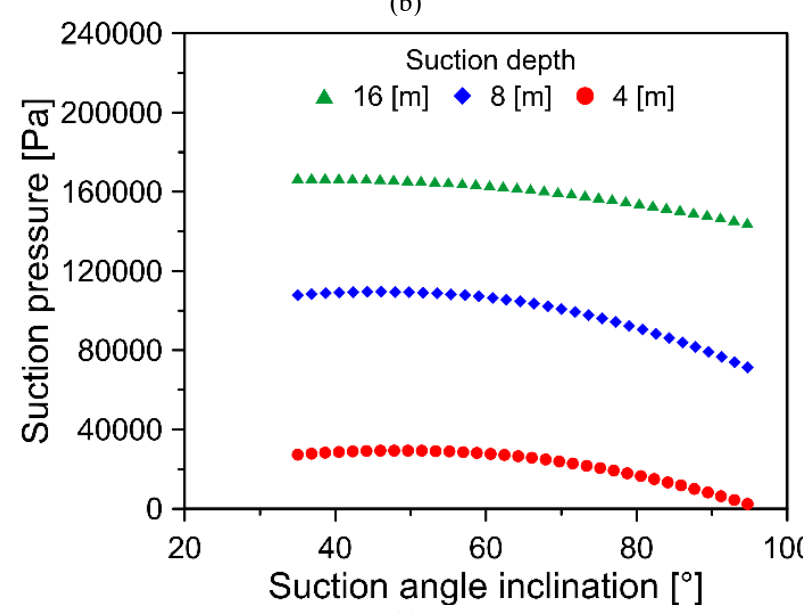

(c)

Fig. 5. Relationship between the suction pressure and the inclination of the suction angle for (a) $0.8 \mathrm{Ton} / \mathrm{m}^{3}$, (b) $1.4 \mathrm{Ton} / \mathrm{m} 3$ and (c) $2 \mathrm{Ton} / \mathrm{m}^{3}$.

Eq. 2 shows the mathematical relationship between the discharge pressure $\left(\mathrm{P}_{\mathrm{D}}\right)$ and the parameters of the suction depth and the flow density. In this case, an adjustment coefficient of $\mathrm{R}^{2}=95.3 \%$ is achieved. Figure 6 shows the graph of the relationship between these two variables.

$$
P_{D}=245912+9874 \cdot(h)-39713 \cdot(\rho)
$$

The results in Figure 6 indicate that the increase in density produces a reduction in the discharge pressure, which is in accordance with the results described in Figure 5.

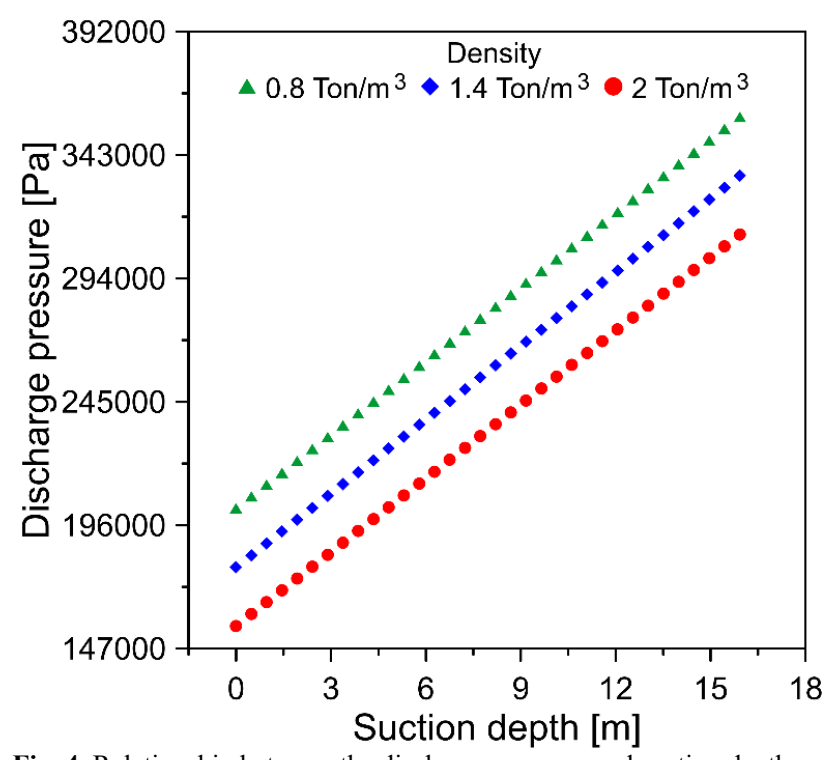

Fig. 4. Relationship between the discharge pressure and suction depth.

The variation of the total dynamic head (TDH) of the pump with respect to the velocity and flow density is shown in Figure 7, which was formed from the mathematical relationship shown in Eq.3.

$$
\begin{aligned}
& \text { TDH }=112.54-0.9215 \cdot(\theta)-31.682 \cdot(\rho)-1.9379 \\
& (\mathrm{~h})+3.529 \cdot(\mathrm{v})+0.002051 \cdot(\theta)^{2}+6.185 \cdot \\
& (\rho)^{2}-0.034868 \cdot(\mathrm{h})^{2}-0.002103 \cdot(\theta) \cdot(\mathrm{h})- \\
& 0.0401 \cdot(\theta) \cdot(\mathrm{v})-0.16365 \cdot(\mathrm{h}) \cdot(\mathrm{v})
\end{aligned}
$$

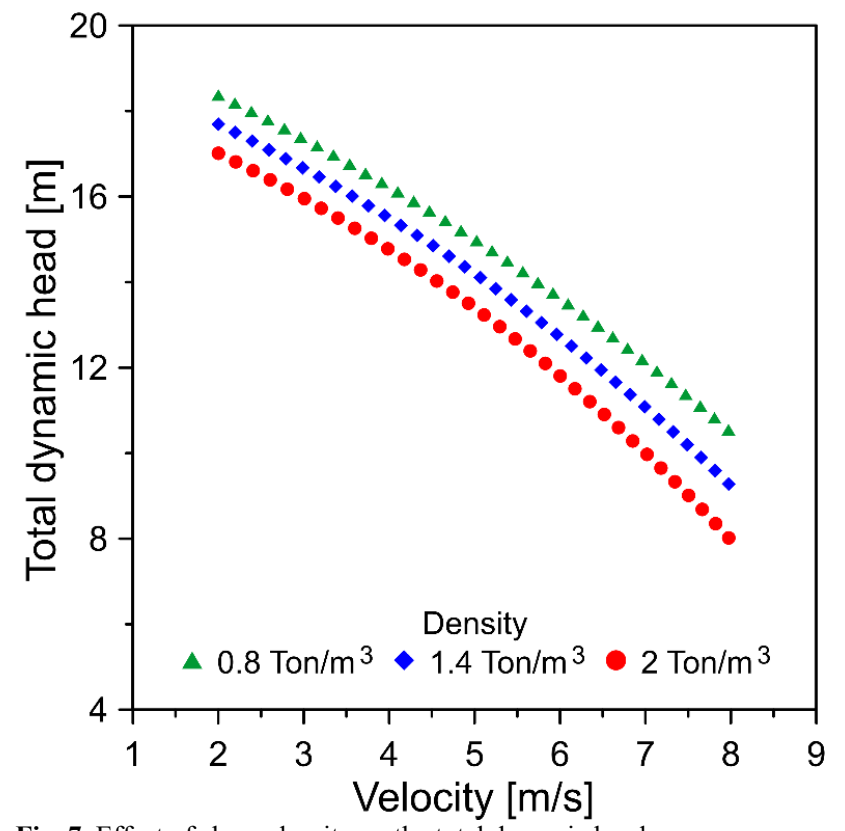

Fig. 7. Effect of slurry density on the total dynamic head.

It is observed that the total dynamic head of the pump decreases with the density of the fluid. This is attributed to the greater energy of kinetic turbulence of the fluid caused by the increase of solid particles. Similar results were recorded in the literature [29]. 
The mathematical model of the NPSH required (NPSHr) output variable is shown in Eq.4. In this case, the adjustment coefficient reached was $\mathrm{R}^{2}=96.43 \%$.

$$
\begin{aligned}
& \text { NPSHr }=-14.678+0.4130 \cdot(\theta)+9.021 \cdot \\
& (\rho)+2.24104 \cdot(\mathrm{h})-3.1835 \cdot(\mathrm{v})-0.002042 \cdot \\
& (\theta)^{2}+6.7985 \cdot(\rho)^{2}+0.040203 \cdot(\mathrm{h})^{2}-0.02584 \cdot \\
& (\mathrm{v})^{2}-0.36731 \cdot(\theta) \cdot(\rho)+0.001946 \cdot(\theta) \cdot \\
& (\mathrm{h})+0.039249 \cdot(\theta) \cdot(\mathrm{v})-2.29790 \cdot(\rho) \cdot \\
& (\mathrm{h})+0.16348 \cdot(\mathrm{h}) \cdot(\mathrm{v})
\end{aligned}
$$

Eq.4 allows analyzing the influence of the flow rate on the NPSHr of the pump. The results of this analysis are shown in Figure 8.

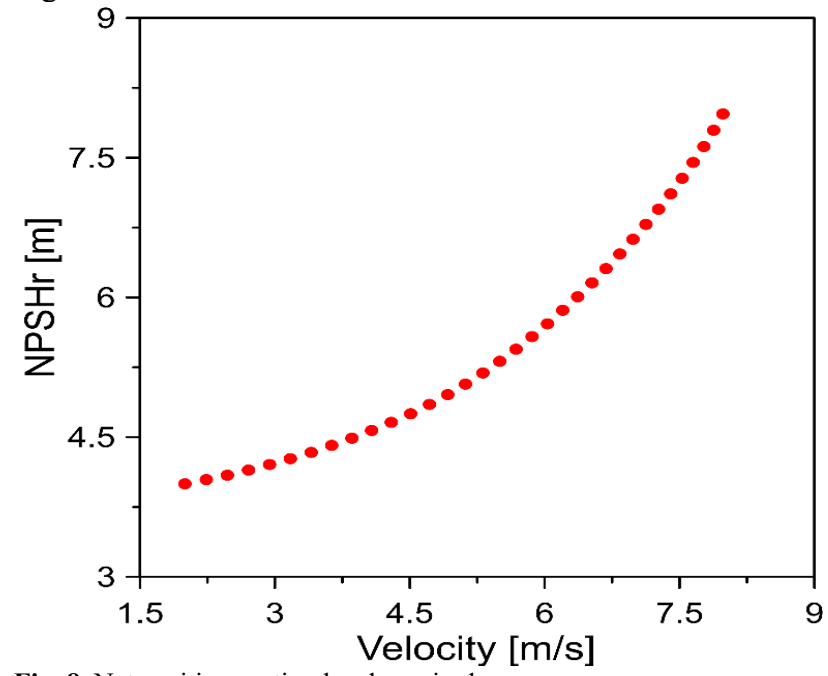

Fig. 8. Net positive suction head required.

It is observed that the increase in flow rate causes a considerable increase in the NPSHr. The above information allows us to define operating limits on the dredge pump to avoid the effects of cavitation.

The predictability of the regression model was evaluated by comparing the pump NPSHr obtained from the experimental data and the mathematical relationships developed. The result of this comparison is shown in Figure 9.

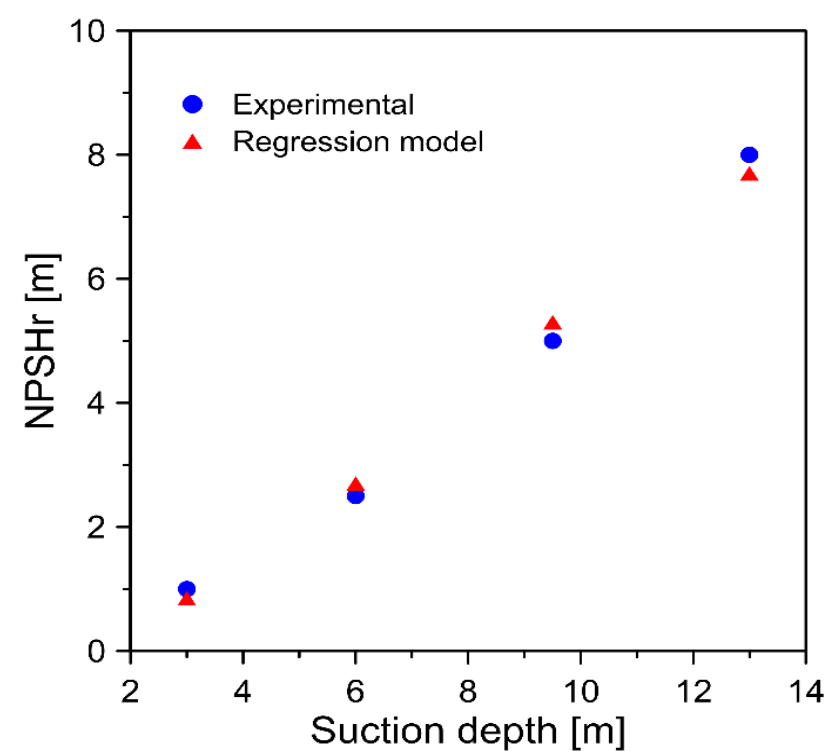

(a)

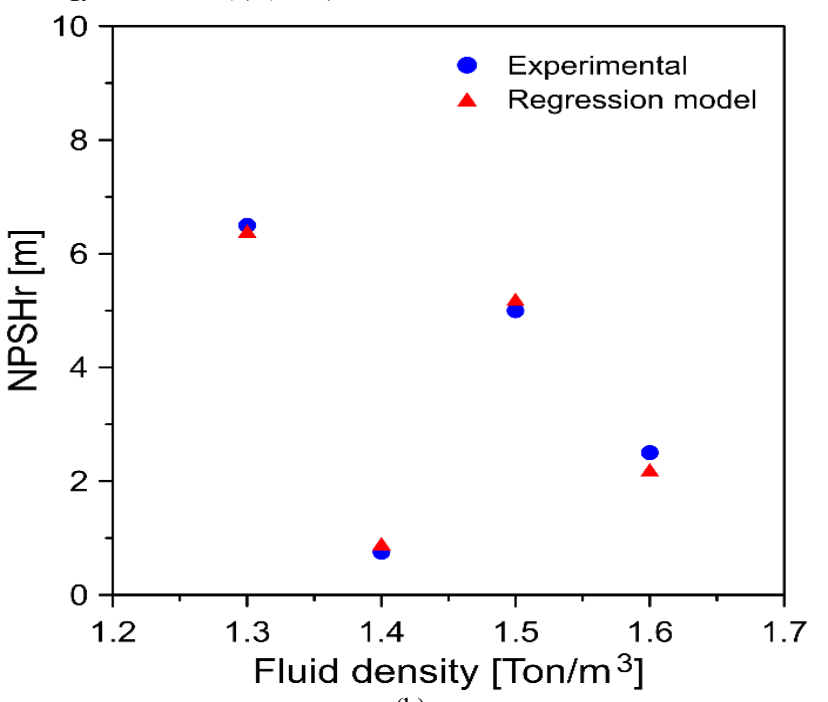

(b)

Fig. 9. Comparison between the NPSHr obtained experimentally and using the regression model according to (a) Suction depth and (b) fluid density.

It is observed that the maximum error between the experimental data and the prediction of the model remained below 3\%. Given the low percentage of this error, the reliability of the mathematical model is verified.

The pump efficiency $(\eta)$ model is shown in Eq.5.

$$
\begin{aligned}
& \eta=502.45-214.71 \cdot(\rho)-50.0986 \cdot(h)+188.766 \cdot \\
& (v)-139.391 \cdot(\rho)^{2}-0.0353556 \cdot(h)^{2}-29.8375 \cdot \\
& (\rho) \cdot(v)+12.7933 \cdot(\rho) \cdot(h)+0.15237 \cdot(h) \cdot(v)
\end{aligned}
$$

Figure 10 shows the influence of the two main input variables in the dredging process (suction depth and flow density). Maximum efficiency of $83 \%$ is observed when a high suction depth has not been raised and the flow density is as low as possible. Any increase in these two input variables causes a reduction in pump efficiency. For the analyzed range, a minimum efficiency of $64 \%$ is recorded. An operating point greater than a density of $2 \mathrm{Ton} / \mathrm{m}^{3}$ or a suction depth greater than $16 \mathrm{~m}$ produces a considerable reduction in efficiency.

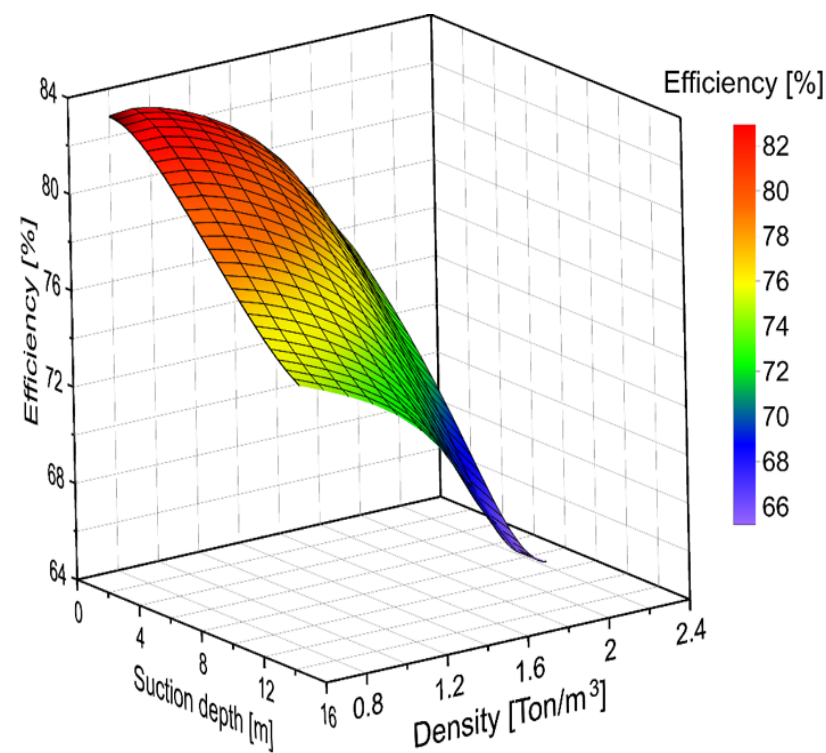

Fig.10. Pump efficiency with respect to density and suction depth parameters. 


\section{Conclusions}

The present study demonstrates the importance of CFD analysis to investigate the operating parameters of a dredge pump. The comparison between the simulated and experimental results remained below $4 \%$, which indicates the reliability of the simulation process. In this way, the economic cost of the studies is drastically reduced, since long and complex experimental trials are not required. Additionally, the CFD analysis allows geometric modifications. In this way, you can find variations that increase the performance of the dredge pump.

The mathematical models of the output variables showed an error below $3 \%$, thus validating the correlations developed. The closeness of the mathematical models with the experimental data is also reflected in the coefficient of adjustment, which remained above $80 \%$ for all created equations.

The development of mathematical correlations allowed us to analyze the effect of the main variables of the dredging process on the efficiency of the pump. A range of variation in efficiency was observed from $83 \%$ to $64 \%$. In this way you can define operating conditions that allow you to maintain adequate performance in the pump and avoid damage due to effects such as cavitation.

\section{Acknowledgments}

The authors thank the UNIVERSIDAD DEL ATLÁNTICO, DRAGADOS HIDRAULICOS S.A., and SPHERE ENERGY company for their support on the development of this research. Also, the authors thank the support provided by engineers Eduar Avila, Robinson Castaño, Kevin Alvear and Miguel Rincón.

This is an Open Access article distributed under the terms of the Creative Commons Attribution License

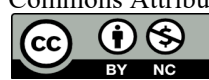

\section{References}

[1] Kassanos, I., Chrysovergis, M., Anagnostopoulos, J., Charalampopoulos, G., Rokas, S., Lekanidis, S., Kontominas, I., Papantonis, D. Numerical Optimization of a Centrifugal Pump Impeller with Splitter Blades Running in Reverse Mode. International Review of Mechanical Engineering (IREME), 10 (4), 2016, 215, ISSN 1970-8742.

[2] Wilson, K. C., Addie, G. R., Sellgren, A., Clift, R. Slurry Transport Using Centrifugal Pumps, Springer (2000). ISBN 9780387232621.

[3] Stefanizzi, M., Torresi, M., Fornarelli, F., Fortunato, B., Camporeale, S. M. Performance prediction model of multistage centrifugal Pumps used as Turbines with Two-Phase Flow. Energy Procedia, 148, 2018, 408-415, ISSN 1876-6102.

[4] Lorusso, M., Capurso, T., Torresi, M., Fortunato, B., Fornarelli, F., Camporeale, S. M., Monteriso, R. Efficient CFD evaluation of the NPSH for centrifugal pumps. Energy Procedia, 126, 2017, 778-785, ISSN 1876-6102.

[5] Cucit, V., Burlon, F., Fenu, G., Furlanetto, R., Pellegrino, F. A., Simonato, M. A control system for preventing cavitation of centrifugal pumps. Energy Procedia, 148, 2018, 242-249, ISSN $1876-6102$.

[6] Cheng, X., Li, R. Parameter equation study for screw centrifugal pump. Procedia Engineering, 31, 2012, 914-921, ISSN 1877-7058.

[7] Skrzypacz, J., Bieganowski, M. The influence of micro grooves on the parameters of the centrifugal pump impeller. International Journal of Mechanical Sciences, 144, 2018, 827-835, ISSN 00207403.

[8] Zhu, X., Li, G., Jiang, W., Fu, L. Experimental and numerical investigation on application of half vane diffusers for centrifugal pump. International Communications in Heat and Mass Transfer, 79, 2016, 114-127, ISSN 0735-1933.

[9] Ye, Y., Zhu, X., Lai, F., Li, G. Application of the semi-analytical cavitation model to flows in a centrifugal pump. International Communications in Heat and Mass Transfer, 86, 2017, 92-100, ISSN 0735-1933.

[10] Capurso, T., Bergamini, L., Torresi, M. Design and CFD performance analysis of a novel impeller for double suction centrifugal pumps. Nuclear Engineering and Design, 341, 2019, 155-166, ISSN 0029-5493.

[11] Yu, R., Liu, J. Failure analysis of centrifugal pump impeller. Engineering Failure Analysis, 92, 2018, 343-349, ISSN 1350-6307.

[12] Chalghoum, I., Elaoud, S., Akrout, M., Taieb, E. H. Transient behavior of a centrifugal pump during starting period. Applied Acoustics, 109, 2016, 82-89, ISSN 0003-682X.

[13] Miedema, S. A. A head loss model for slurry transport in the heterogeneous regime. Ocean Engineering, 106, 2015, 360-370, ISSN 00298018.

[14] Derakhshan, S., Nourbakhsh, A. Theoretical, numerical and experimental investigation of centrifugal pumps in reverse operation. Experimental Thermal and Fluid Science, 32 (8), 2008, 1620-1627,
ISSN 08941777.

[15] Roco, M. C., Addie, G. R., Visintainer, R. Study on casing performances in centrifugal slurry pumps. Particulate Science and Technology, 3 (1-2), 2007, 65-88, ISSN 15480046.

[16] Yoo, I. S., Park, M. R., Chung, M. K. Improved momentum exchange theory for incompressible regenerative turbomachines. Proceedings of the Institution of Mechanical Engineers, Part A: Journal of Power and Energy, 219 (7), 2005, 567-581, ISSN 09576509.

[17] Casari, N., Fadiga, E., Pinelli, M., Randi, S., Suman, A. Pressure Pulsation and Cavitation Phenomena in a Micro-ORC System. Energies, 12 (11), 2019, 2186, ISSN 1996-1073.

[18] Ragoth Singh, R., Nataraj, M., Surendar, S., Siva, M. Investigation of a centrifugal pump impeller vane profile using CFD. International Review on Modelling and Simulations, 6 (2), 2013, 1327-1333, ISSN 25331701.

[19] Al Asemi, H., S. M. A., A., Zahari, R., Aziz, F. A., Ahmad, K. A. Application of Computational Fluid Dynamics in Piping Distribution System and Special Focus on the Arabian Peninsula: a Review. International Review of Mechanical Engineering (IREME), 13 (1), 2019, 1, ISSN 2532-5655.

[20] Maluta, F., Paglianti, A., Montante, G. RANS-based predictions of dense solid-liquid suspensions in turbulent stirred tanks. Chemical Engineering Research and Design, 147, 2019, 470-482, ISSN 02638762 .

[21] Heng, J., New, T. H., Wilson, P. A. Application of an Eulerian granular numerical model to an industrial scale pneumatic conveying pipeline. Advanced Powder Technology, 30 (2), 2019, 240-256, ISSN 09218831.

[22] Tarodiya, R., Gandhi, B. K. Numerical simulation of a centrifugal slurry pump handling solid-liquid mixture: Effect of solids on flow field and performance. Advanced Powder Technology, 30 (10), 2019, 2225-2239, ISSN 09218831.

[23] Quail, F. J., Scanlon, T., Baumgartner, A. Design study of a regenerative pump using one-dimensional and three-dimensional numerical techniques. European Journal of Mechanics, B/Fluids, 31 (1), 2012, 181-187, ISSN 09977546.

[24] Badami, M., Mura, M. Comparison between 3D and 1D simulations of a regenerative blower for fuel cell applications. Energy Conversion and Management, 55, 2012, 93-100, ISSN 01968904.

[25] Yousefi, H., Noorollahi, Y., Tahani, M., Fahimi, R., Saremian, S. Numerical simulation for obtaining optimal impeller's blade parameters of a centrifugal pump for high-viscosity fluid pumping. Sustainable Energy Technologies and Assessments, 34, 2019, 16-26, ISSN 22131388.

[26] Hofstra, C. F., Rhee, C. van, Miedema, S. A., Talmon, A. M. On The Particle Trajectories In Dredge Pump Impellers. 14th International Conference Transport \& Sedimentation Of Solid Particles, Saint Petersburg, Russia, 2008. 
Journal of Engineering Science and Technology Review 13 (3) (2020) 8 - 14

[27] Grabow, G. Two-phase flow in centrifugal pumps for hydraulic solids transport. Engineering Research, 70 (1), 2005, 1-12, ISSN 00157899.

[28] Zhao, W., Zhao, G. Numerical investigation on the transient characteristics of sediment-laden two-phase flow in a centrifugal pump. Journal of Mechanical Science and Technology, 32 (1), 2018,

\section{7-176, ISSN 1738-494X.}

[29] Li, Y., Zhu, Z., He, W., He, Z. Numerical simulation and experimental research on the influence of solid-phase characteristics on centrifugal pump performance. Chinese Journal of Mechanical Engineering, 25 (6), 2012, 1184-1189, ISSN 1000-9345. 